
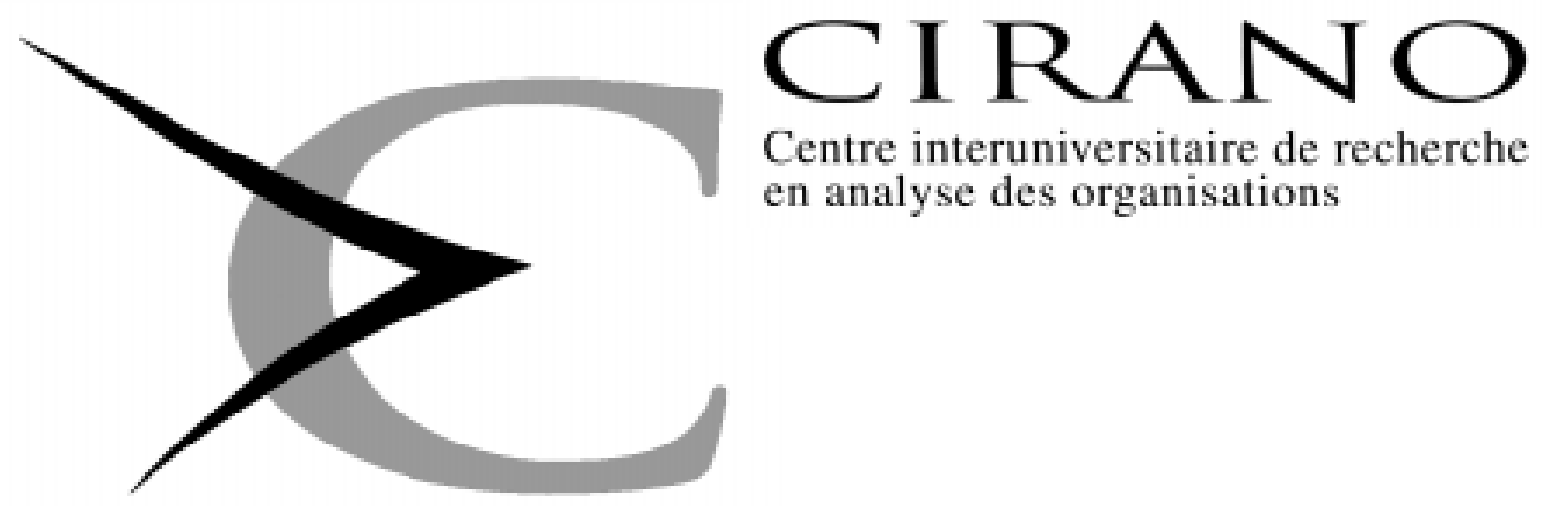

Centre interuniversitaire de recherche en analyse des organisations

Série Scientifique

Scientific Series

97s-21

\title{
Efficiency Inducing \\ Taxation for \\ Polluting Oligopolists
}

Hassan Benchekroun, Ngo Van Long 


\section{CIRANO}

Le CIRANO est une corporation privée à but non lucratif constituée en vertu de la Loi des compagnies du Québec. Le financement de son infrastructure et de ses activités de recherche provient des cotisations de ses organisations-membres, d'une subvention d'infrastructure du ministère de l'Industrie, du Commerce, de la Science et de la Technologie, de même que des subventions et mandats obtenus par ses équipes de recherche. La Série Scientifique est la réalisation d'une des missions que s'est données le CIRANO, soit de développer l'analyse scientifique des organisations et des comportements stratégiques.

CIRANO is a private non-profit organization incorporated under the Québec Companies Act. Its infrastructure and research activities are funded through fees paid by member organizations, an infrastructure grant from the Ministère de l'Industrie, du Commerce, de la Science et de la Technologie, and grants and research mandates obtained by its research teams. The Scientific Series fulfils one of the missions of CIRANO: to develop the scientific analysis of organizations and strategic behaviour.

\section{Les organisations-partenaires / The Partner Organizations}

•École des Hautes Études Commerciales

-École Polytechnique

-McGill University

-Université de Montréal

-Université du Québec à Montréal

-Université Laval

-MEQ

-MICST

-Avenor

-Banque Nationale du Canada

-Bell Québec

- Caisse de dépôt et de placement du Québec

-Fédération des caisses populaires Desjardins de Montréal et de l'Ouest-du-Québec

-Hydro-Québec

-Raymond, Chabot, Martin, Paré

-Société d'électrolyse et de chimie Alcan Ltée

-Téléglobe Canada

-Ville de Montréal

Ce document est publié dans l'intention de rendre accessibles les résultats préliminaires de la recherche effectuée au CIRANO, afin de susciter des échanges et des suggestions. Les idées et les opinions émises sont sous l'unique responsabilité des auteurs, et ne représentent pas nécessairement les positions du CIRANO ou de ses partenaires.

This paper presents preliminary research carried out at CIRANO and aims to encourage discussion and comment. The observations and viewpoints expressed are the sole responsibility of the authors. They do not necessarily represent positions of CIRANO or its partners.

ISSN 1198-8177 


\title{
Efficiency Inducing Taxation for Polluting Oligopolists
}

\author{
Hassan Benchekroun $n^{\dagger}$ Ngo Van Long
}

\author{
Résumé / Abstract
}

\begin{abstract}
Règle de taxation permettant de réaliser l'optimalité pour un oligopole polluant. On considère une industrie oligopolistique dans laquelle la production s'accompagne d'émissions de pollution qui s'accumule pour former un stock. Dans ce modèle, les firmes se livrent une concurrence à la Cournot. Le gouvernement propose une règle de taxation pour corriger à la fois l'effet de la concurrence imparfaite et l'externalité négative due aux émissions de pollution. On montre qu'il existe une règle de taxation qui ne dépend pas explicitement du temps et qui amène les firmes à choisir le sentier de production socialement optimal. Le taux optimal de taxation d'unité de production dépend du niveau du stock de pollution et peut être négatif (une subvention) pour des niveaux faibles du stock de pollution. On obtient un résultat qui peut sembler surprenant à première vue: il peut être optimal de subventionner la production pour au moins une période de temps, même si la production de la situation de laisser-faire (sans intervention) est à chaque instant au dessus du niveau de production socialement optimal. Malgré la subvention, les firmes réduisent leur production par rapport à la situation de laisser-faire afin de prolonger la période de subvention et retarder le moment ol'u la subvention se transformerait en taxe.
\end{abstract}

We derive corrective tax rules when firms are oligopolists whose production processes generate emissions that add to a stock of pollution that accumulates over time. In our model, firms play dynamic Cournot games among themselves, and the government designs a tax rule that corrects for both the externality associated with emissions and the market power of oligopolists. We show that there exists a time-independent tax rule that guides the oligopolists to achieve the socially optimum production path. The optimal tax per unit of output is dependent on the current level of the pollution stock, and it may be negative (implying a subsidy) when the pollution stock is low. We obtain a rather surprising result: in some cases, the optimal tax rule gives firms a subsidy for an initial time interval even though under laissez-faire their output exceeds the socially optimal output at each point of time. This subsidy, however, induces firms to produce less than they would under laissez-faire, because they know that if they produce more then the subsidy will be reduced in the future and/or will soon turn into a tax.

\footnotetext{
"Correspondence Address: Ngo Van Long, CIRANO, 2020 University Street, 25th floor, Montréal, Qc, Canada H3A 2A5 Tel: (514) 985-4011 Fax: (514) 985-4039 e-mail: longn@ cirano.umontreal.ca We thank Gerhard Sorger for helpful comments. This research is supported by SSHRC.

† Université Laval and GREEN

McGill University and CIRANO
} 
Mots Clés : $\quad$ Pollution, oligopole, taxation, incitation, jeux dynamiques

Keywords : $\quad$ Pollution, oligopoly, taxation, incentive, dynamic games

JEL : H41, L51, Q25 


\section{Introduction}

When firms' production process generates pollutants as a byproduct, this externality must be corrected. Among the methods of correction advocated by economists are (i) imposing pollution standards, (ii) taxing polluting firms, (iii) requiring firms to buy pollution permits, (iv) relying on bargaining between the firms and the injured party, and (v) threat of litigations. All these methods have well- known advantages as well as drawbacks. For example, an oligopolist might purchase all or most of the permits, thus improving its market share and possibly leading to monopolisation of the industry ${ }^{1}$. Bargaining and litigations may involve considerable transaction costs. Taxation and standards may require information that the regulator does not possess.

In this paper, we do not take a position on the choice of policy instruments. Our aim is to characterize the optimal tax rule when the emission of pollutants by firms causes present as well as future damages because the stock of pollution accumulates over time. Specifically, we assume that firms are oligopolists, so that each firm does realize that the future actions of its rivals depend on its own present action. Firms maximize their long-run profit, anticipating both the actions of their rivals, and the future tax rates that reflect future environmental damages. We are able to show that even if firms play dynamic games among themselves, it is possible to construct tax rules that achieve efficiency. By considering the taxing of polluting oligopolists in a dynamic context, we depart from the static oligopoly framework used in Katsoulacos and Xepapadeas (1992) and Kennedy (1994).

The optimum tax rule must send to firms the message that the more they pollute now, the higher will be their future tax liability. The parameters of the tax rule, however, depend on how firms interact with each other in a dynamic Nash equilibrium: they may play an openloop game, or a closed-loop game. This distinction will be explained below. We show that in both cases, there exists a corresponding timeindependent tax rule that guides the oligopolists to achieve the socially optimum time paths of production and pollution. The optimal tax per unit of output is dependent on the current level of the pollution stock, and it may be negative (implying a subsidy) when the pollution stock is low. We obtain a result that might at first seem puzzling: in some cases, under the optimal tax rule, firms receive a subsidy for some initial time interval even though under laissez-faire their output exceeds the

\footnotetext{
${ }^{1}$ See Newbery (1990, pp. 344-345), von der Fehr (1993), Sartzetakis (1996), Long and Soubeyran (1997), among others. Laffont and Tirole (1996a,b) address some asymmetric information issues associated with pollution permits.
} 
socially optimal output at each point of time. This subsidy, however, induces firms to produce less than they would under laissez-faire, because they know that if they produce more then the subsidy will be reduced in the future and/or will soon turn into a tax. Upon reflection, this is an instance of "the carrot and the stick" policies.

The literature on regulating (or taxing) firms in a dynamic context consists mainly of two streams. The first one focuses on informational issue without paying much attention to the problem of stock accumulation $^{2}$. The second stream deals with stock dynamics and assume perfect information ${ }^{3}$. In addition, there are a few articles that link the two streams ${ }^{4}$. The present paper belongs to the second stream. In its concern with efficiency-inducing taxation, it is inspired by the models of Bergstrom, Cross and Porter (1981)- to be referred to as BCP- and Karp and Livernois $(1992,1994)$. BCP deal with the design of a tax scheme in the case of a monopoly that exploits an exhaustible resource. They derive an intuitively appealing family of tax/subsidy schedules that ensure efficient output level. Karp and Livernois (1992) show that the BCP rules, being time-dependent, are subject to strategic manipulation by the monopolist if the government is unable to commit to the entire sequence of tax rates. In other words, the $\mathrm{BCP}$ tax rules are not subgame perfect. Karp and Livernois (1992) propose instead a linear Markov perfect (LMP) tax rule which ensures subgame perfection and induces the monopolist to produce the efficient output level.

The case of oligopoly is more complicated, because of intertemporal strategic interaction among firms. The only dynamic model of a polluting oligopoly that we are aware of is Karp and Livernois (1994). They restrict attention to the case in which the regulator does not seek to maximize welfare, but only aims at reducing aggregate emissions to an

\footnotetext{
${ }^{2}$ See Baron (1989), Besanko and Sappington (1987) on the designs of regulatary mechanisms under limited information (i.e. there is at least one variable that the regulator cannot observe) using the revelation principle, which is central to such designs. Laffont and Tirole (1988) show that when there is learning (informational dynamics) the revelation principle breaks down in the absence of commitment. Sappington and Sibley (1988) show that if profits can be observed with one-period lag, then using the incremental surplus subsidy (ISS) scheme, the regulator can induce a monopolist to produce the efficient output level even if the regulator does not know the firm's cost function. In the case of a monopolist that extracts from a stock of exhaustible resource, Karp and Livernois (1992) show that ISS must be supplemented by an exit $\operatorname{tax}$.

${ }^{3}$ For regulating a monopoly, see Bergstrom, Cross and Porter (1981), and the first part of Karp and Livernois (1992). Farzin (1996) addresses dynamic aspects of pollution tax under the assumption of perfect competition.

${ }^{4}$ See Karp and Livernois (1992), (1994), Gaudet, Lassere and Long (1995, 1996a, $1996 \mathrm{~b})$.
} 
exogenously specified target level. Furthermore, in their model there is no stock of pollution; the state variable in the model is the tax rate that gets adjusted when actual emission differs from the target level. Our model is different in two respects: first, the government seeks to induce the efficient time path of pollution; second, the stock of pollution accumulates with emissions. By having the tax rate conditioned on the stock of pollution, our model has more on common with Karp and Livernois (1992), but that paper deals with a monopolist extracting a non-renewable resource while we are concerned with an oligopoly that impacts on a renewable resource (the quality of the environment); this oligopolistic struture introduces new strategic elements. On the other hand, we assume perfect information, while Karp and Livernois (1992) also consider the case of imperfect information.

Before deriving the optimal tax rule, we start with the case where the government announces from the outset an arbitrary tax rule, and we show how firms respond to this tax rule while playing a non-cooperative game among themselves. We focus on linear Markov tax rule, that is, the tax bill at any time $t$ depends only on the current levels of output and pollution stock, and it is linear in the firm's output, though not necessarily linear in the pollution stock.

We study two types of equilibria, which differ on the information firms use to condition their actions. In the open-loop Nash equilibrium (OLNE), each firm chooses, right at the beginning of the game, its time path of production (and hence emission), taking as given the time paths chosen by other firms. In the Markov Perfect Nash Equilibrium (MPNE), each firm chooses a feedback strategy, that is, a decision rule which conditions its output at any time $t$ on the level of the pollution stock observed at that time ${ }^{5}$. Both types of equilibria are time-consistent, in the sense that if all firms follow their strategies, then at each point in time no firm will have an incentive to deviate. A requirement that is stronger than time-consistency is 'subgame perfection'. It is known that the MPNE is subgame perfect but the OLNE is not ${ }^{6}$.

While subgame perfection is a very important criterion for equilibrium selection, especially because it eliminates Nash equilibria that are made possible only by non-credible threats, this does not mean that OLNE should be discarded. In many simultaneous-move games where agents are symmetric (such as the oligopoly game considered here), 'unreasonable' equilibria brought about by non-credible threats do not arise.

\footnotetext{
${ }^{5}$ This structure is often referred to as the closed-loop information structure; see Fudenberg and Tirole (1991, Sections 4.7 and 13.3), for further discussion.

${ }^{6}$ For further explanation of these concepts and several interesting examples, see Karp and Newbery (1993).
} 
Furthermore, as Fudenberg and Tirole (1991, p.131) point out, OLNE "serve as a useful benchmark for discussing the effects of strategic incentives in the closed-loop information structure."

In this paper, we compare the OLNE with the MPNE, and show that the optimal tax rules in the two equilibria take similar forms, but with different parameter values. In both cases, the first best pollution path is shown to be achievable by an appropriate linear Markov tax rule. The correct parameters for the tax rules depend on whether firms choose open-loop or Markov strategies. Thus our results indicate that informational problems facing the government are not restricted to the task of finding out the true damage function, demand curve and cost parameters; the government must also find out whether firms use open-loop or Markov strategies, or perhaps guide firms in their choice of strategies.

In Section 2, we describe the basic model and characterize the social optimum. The corrective tax rules are derived in Sections 3 and 4 for the open-loop and feedback cases respectively. Section 5 offers some final remarks.

\section{The Basic Model}

We consider an oligopoly consisting of $n$ identical firms that produce a homogeneous good. Each firm has a constant unit cost $c \geq 0$. Let $q_{i}$ denote firm $i$ 's output. Industry output is $Q=\sum q_{i}$ and the inverse demand function is $P=P(Q)$, with $P^{\prime}<0$ and $P(0)>c$. The amount of pollutant emitted by firm $i$ is $e_{i}=\mu q_{i}$ where $\mu>0$. Without loss of generality, we set $\mu=1$. Let $S \geq 0$ denote the stock of pollution. Following Forster (1973) we assume that the dynamics of the pollution stock obeys the law

$$
\dot{S}(t)=Q(t)-\delta S(t)
$$

where $\delta>0$ is rate of decay of the pollution stock.

The social welfare at time $t$ is assumed to be of the separable form

$$
W(t)=U(Q(t))-c Q(t)-\gamma D(S(t))
$$

where $\gamma D(S) \geq 0$ is the damage function representing the harm caused by the stock of pollution. The parameter $\gamma \geq 0$ allows us to do comparative statics and to consider the polar case where the pollution does not affect welfare, i.e. $\gamma=0$. We take $U(Q)$ to be the area under the demand curve:

$$
U(Q)=\int_{0}^{Q} P(Z) d Z
$$


It is assumed that the function $D(S)$ is strictly convex, and that the marginal damage is negligible if the stock of pollution is zero:

$$
D(0)=0, \quad D^{\prime}(0)=0, \quad D^{\prime}(S)>0 \quad \text { for } S>0, \quad D^{\prime \prime}(S)>0 .
$$

As we will see below, this assumption ensures that there is a unique and positive steady state level of pollution under the central planning scenario.

The aggregate welfare is defined as the integral of the discounted stream of $W(t)$ :

$$
V=\int_{0}^{\infty} W(t) e^{-r t} d t
$$

where $r>0$ is the rate of discount.

\section{The Social Optimum}

Before describing the behaviour of firms, let us find out what is the optimum solution if firms can be directly controlled by a benevolent 'social planner'. This, of course, is only a theoretical benchmark case, and should not be taken as our endorsement of direct control of production by any central agency. The social planner chooses the time path of the industry output, $Q(t)$, so as to maximize (3) subject to $\dot{S}=Q-\delta S$ and the given initial condition $S(0)=S_{0}$. This is a standard optimal control problem with an infinite horizon ${ }^{7}$. Let $\lambda$ denote the shadow price of the pollution stock. It will be shown that $\lambda$ is negative along the optimal path. The necessary conditions are

$$
\begin{gathered}
P(Q)-c+\lambda \leq 0, \quad Q[P(Q)-c+\lambda]=0 \\
\dot{\lambda}=\lambda(\delta+r)+\gamma D^{\prime}(S) \\
\dot{S}=Q-\delta S
\end{gathered}
$$

and the transversality condition is

$$
\lim _{t \rightarrow \infty} e^{-r t} \lambda(t) S(t)=0
$$

When $Q$ is strictly positive, (4) and (5) yield the following condition

$$
P^{\prime}(Q) \dot{Q}=-\dot{\lambda}=(r+\delta)[P(Q)-c]-\gamma D^{\prime}(S)
$$

\footnotetext{
${ }^{7}$ See, for example, Léonard and Long (1992) for the solution techniques for this type of optimal control problems.
} 
From (6) and (8) the steady state can be determined. There exists a unique optimal steady state level of the pollution stock, denoted by $\widehat{S}_{\infty}$, and a corresponding steady state output level

$$
\widehat{Q}_{\infty}=\delta \widehat{S}_{\infty}
$$

where $\widehat{S}_{\infty}$ satisfies the following equation

$$
P\left(\delta \widehat{S}_{\infty}\right)=c+\frac{\gamma D^{\prime}\left(\widehat{S}_{\infty}\right)}{r+\delta}
$$

This condition says that, at the steady state, the consumers' valuation of the marginal unit of output must be equal to its production cost plus the present value of the stream of marginal damage caused by the additional pollution generated by it.

It can be shown that, starting with any initial pollution stock $S_{0}<$ $\widehat{S}_{\infty}$ the optimal time path of $S$ is monotone increasing, approaching $\widehat{S}_{\infty}$ as $t$ tends to infinity. The associated time path of production $Q(t)$ is positive and monotone decreasing ${ }^{8}$ if $\gamma>0$, approaching $Q_{\infty}$ asymptotically. If $S_{0}>\widehat{S}_{\infty}$ then the optimal time path of $S$ is monotone decreasing and $Q$ is monotone increasing except possibly for some initial time interval where there is no production, and this happens only if $S_{0}$ is very great, say $S_{0}>\bar{S}$ where $\bar{S}$ is a large number. It follows that for all initial condition $S_{0} \geq 0$ the optimal output at any time $t$ can be expressed as a function of the optimal stock level $S$ at $t$. We denote this functional relationship, for all $S \geq 0$, as $Q=\widehat{Q}(S) \geq 0$, with

$$
\begin{gathered}
\widehat{Q}^{\prime}(S)<0 \text { if } S<\bar{S} \text { and } \gamma>0, \quad \widehat{Q}(S)=0 \text { if } S \geq \bar{S} \\
\widehat{Q}\left(\widehat{S}_{\infty}\right)=\delta \widehat{S}_{\infty}
\end{gathered}
$$

This functional relationship will be referred to as the 'feedback control rule'. It describes the optimal control rule in the feedback form: given the current level of the stock, the optimal current production $Q$ is uniquely determined $^{9}$.

\section{The linear-quadratic case}

Consider the special case where the function $P(Q)$ is linear and the function $D(S)$ is quadratic,

$$
P(Q)=P(0)-b Q, \quad P(0)-c \equiv a>0
$$

\footnotetext{
${ }^{8}$ If $\gamma=0$ then $Q(t)$ is constant over the whole time horizon.

${ }^{9}$ Technically, the function $Q(S)$ thus described represents the stable branch of the saddle-point in the $(Q, S)$ phase diagram.
} 
and

$$
\gamma D(S)=\frac{\gamma S^{2}}{2} \quad \text { for } S \geq 0, \quad \gamma>0
$$

The steady state is

$$
\widehat{S}_{\infty}=\frac{a(r+\delta)}{(r+\delta) b \delta+\gamma}
$$

And the feedback control rule $\widehat{Q}(S)$ can be shown to be linear and decreasing in $S$ :

$$
\widehat{Q}(S)=\widehat{Q}_{\infty}+\rho\left[S-\widehat{S}_{\infty}\right]=\rho S+(\delta-\rho) \widehat{S}_{\infty}
$$

where $\rho$ is a negative root of the quadratic equation

$$
\rho^{2}-(r+2 \delta) \rho-(\gamma / b)=0
$$

Remark: Strictly speaking, (16) holds only for $0 \leq S \leq \bar{S}$, where

$$
\bar{S}=\widehat{S}_{\infty}-\frac{\widehat{Q}_{\infty}}{\rho}>\widehat{S}_{\infty}
$$

and $\widehat{Q}=0$ is $S>\bar{S}$.

\section{Oligopolistic Behavior}

We now return to the market economy scenario. Firms are not subject to direct control from a central government agency. They are free to choose their output levels. However they have to pay taxes. We restrict attention to the case where each firm's tax bill at time $t$ is a function of its current output level $q_{i}(t)$ and of the size of the pollution stock $S(t)$. Furthermore, we assume that "equals must be treated equally": all firms face the same tax rule ${ }^{10}$. We denote firm $i$ 's tax bill at time $t$ by

$$
T_{i}=T\left(S(t), q_{i}(t)\right)
$$

where the functional form $T(.,$.$) is the same for all firms. This tax rule$ contains $S$ as an argument because we would expect the government to want firms to internalize the social cost they cause by their emission of pollutants. In what follows, we consider only rules that are linear in output: $T\left(S, q_{i}\right)=\tau(S) q_{i}$; in other words, we restrict attention to stationary Markov tax rules that are linear in output. These are called

\footnotetext{
${ }^{10}$ It may be optimal to treat equals unequally. See Long and Soubeyran (1997). In the present paper we impose the requirement that equals must be treated equally, to reflect the fact that in many societies, discrimination is illegal.
} 
linear Markov (LM) tax rules. We could have dealt with a more general class of tax rules. For example, a tax rule could state the tax rate as function of the calendar time, which would permit us to look at the case where the government can precommit to a time path of non-constant tax rate. In fact, Bergstrom, Cross, and Porter (1981), in dealing with efficiency-inducing tax for a monopolist mining firm, assume that the per unit tax rate $\tau$ is a function of time alone. However, as pointed out by Karp and Livernois (1992), if the government cannot precommit to its announced time path of tax rate, any tax rule that depends on calendar time is subject to strategic manipulation by the monopolist (in our case, the oligopolists) and will not achieve efficiency. For this reason, we restrict attention to tax rules that are independent of time.

Firm $i$ 's profit at time $t$ is

$$
\pi_{i}(t)=P\left[q_{i}(t)+Q_{-i}(t)\right] q_{i}(t)-[c+\tau(S(t))] q_{i}(t)
$$

where $Q_{-i}(t)$ denotes the sum of the outputs of all other firms. We assume that firms take a long view and therefore do not maximize shortrun profit. Each firm realizes that its output at $t$ will add to the pollution stock, and thus affect its future tax liability. Firm $i$ 's objective function is to maximize its long-run profit, defined as the value $\Pi_{i}$ of the stream of discounted short-run profits:

$$
\Pi_{i}=\int_{0}^{\infty} \pi_{i}(t) e^{-r t} d t
$$

We seek to characterize the Nash equilibria of the game for a given tax rule, and then find the optimum tax rule. As one would expect, this depends on the type of Nash equilibrium under consideration. In the next two sections, we examine two types of equilibrium: open-loop Nash equilibrium (OLNE) and Markov Perfect Nash Equilibrium (MPNE).

\section{Corrective Tax in an Open-loop Nash Equi- librium}

In the open-loop formulation, the strategy space for each firm is the set of all possible time paths of its output, and each firm must choose right at the beginning of the game (at $t=0)$ its entire time path $q_{i}($.$) . An open-$ loop Nash equilibrium (OLNE) for the industry is a set of chosen time paths, $q_{1}(),. \ldots, q_{n}($.$) , such that each firm's chosen time path maximizes$ its long-run profit, given the time paths chosen by other firms. Any firm can at any time $t>0$ revise its time path, but whenever it contemplates 
a revision, it continues to assume that all other firms will stick to their originally chosen time paths $q_{j}(),. j \neq i$. In the literature on open-loop Nash equilibrium, it has been proved that along the equilibrium play, at no time a firm can gain by departing from its initial plan. In other words, open-loop Nash equilibria are time-consistent. (See Karp and Newbery (1993) for a discussion of the time-consistency issue.)

In what follows, we describe the open-loop Nash equilibrium of the pollution game. At time $t=0$, the government announces the per unit tax rule $\tau(S)$ that is applicable to all firms, at all time. By definition, in an OLNE each firm has the correct forecast of the time paths of output of all other firms. Firm $i$ 's chosen time path must be the solution of the following optimal control problem

$$
\max \int_{0}^{\infty}\left\{P\left(Q_{-i}+q_{i}\right)-c-\tau(S)\right\} q_{i} e^{-r t} d t
$$

subject to

$$
\dot{S}=Q_{-i}+q_{i}-\delta S
$$

and $q_{i} \geq 0, S(0)=S_{0}$. Here, $Q_{-i}(t)$ is taken as given.

Let $\lambda_{i}$ be the shadow price of the pollution stock in firm $i$ 's optimal control problem. The necessary conditions for an interior maximum are (21) and

$$
\begin{gathered}
P-c+q_{i} P^{\prime}-\tau(S)=-\lambda_{i} \\
\dot{\lambda}_{i}=\lambda_{i}(r+\delta)+q_{i} \tau^{\prime}
\end{gathered}
$$

The transversality condition is

$$
\lim _{t \rightarrow \infty} e^{-r t} \lambda_{i}(t) S(t)=0
$$

We will consider only symmetric equilibria, where all firms behave identically. Obviously if the tax function is independent of $S\left(\tau^{\prime}\right.$ is zero identically, and hence $\tau=k$ a constant), then no firm will care about the pollution stock and hence $\lambda_{i}=0$; in this case we obtain the usual static oligopolistic equilibrium, and the industry output is a constant over time. If $\tau=0$ identically then $Q(t)=\bar{Q}$ where

$$
P(\bar{Q})+(\bar{Q} / n) P^{\prime}(\bar{Q})=c
$$

We call $\bar{Q}$ the laissez-faire level of output. If the per unit tax rate does depend on $S$ then $\lambda$ is non-zero. From (22) and (23):

$$
\frac{P^{\prime}}{n}[n+1-R] \dot{Q}=\left[P-c-\tau+\frac{Q}{n} P^{\prime}\right](r+\delta)+\left[\dot{S}-\frac{Q}{n}\right] \tau^{\prime}
$$


where $R \equiv-Q P^{\prime \prime} / P^{\prime}$ is the elasticity of the slope of the demand curve, which is assumed to be less than $n+1$; this assumption is a familiar stability condition in static oligopoly theory, see Dixit (1986), for example. From (25) the steady state pollution stock in an OLNE, denoted by $S_{\infty}^{o l}$, must satisfy the following condition

$$
P\left(\delta S_{\infty}^{o l}\right)=c+\tau\left(S_{\infty}^{o l}\right)+\left[\frac{\delta S_{\infty}^{o l}}{n}\right]\left[\frac{\tau^{\prime}\left(S_{\infty}^{o l}\right)}{r+\delta}-P^{\prime}\left(\delta S_{\infty}^{o l}\right)\right]
$$

Substituting $Q=\dot{S}+\delta S$ and $\dot{Q}=\ddot{S}+\delta \dot{S}$ into (25), we obtain a second order differential equation in $S$. We choose the solution that leads to the steady state, that is the point $(\dot{S}, S)=\left(0, S_{\infty}^{o l}\right)$. The OLNE may be represented by a pair of time paths for the stock $S(t)$ and the output $Q(t)$, and we denote their steady state values by $S_{\infty}^{o l}$ and $Q_{\infty}^{o l}$. In the $(S, Q)$ space, this pair $(S(t), Q(t))$ can be represented by a function $Q=$ $Q^{o l}(S)$ which may be called the 'feedback representation' of the OLNE. (See the appendix for an example of such a feedback representation.)

Our task is to design a tax rule $\tau(S)$ such that the socially optimum time path of pollution can be "decentralized" as an OLNE of the dynamic game played by the oligopolists. The following proposition characterizes the optimal tax rule:

Proposition 1 (Optimal tax rule for OLNE: the general case)

Suppose that firms use open-loop strategies, and the government wishes to design a tax rule that guides them to achieve the socially optimal path $\widehat{Q}(S)$. The optimal tax rule $\tau(S)$ is the solution of the following linear differential equation

$$
\tau(S)+A(S) \tau^{\prime}(S)=B(S)
$$

with the boundary condition

$$
P\left(\delta \widehat{S}_{\infty}\right)=c+\tau\left(\widehat{S}_{\infty}\right)+\left[\frac{\delta \widehat{S}_{\infty}}{n}\right]\left[\frac{\tau^{\prime}\left(\widehat{S}_{\infty}\right)}{r+\delta}-P^{\prime}\left(\delta \widehat{S}_{\infty}\right)\right]
$$

where

$$
A(S)=\frac{n \delta S-(n-1) \widehat{Q}(S)}{n(r+\delta)}
$$

and

$$
B(S)=P-c-\frac{\widehat{Q}}{n} P^{\prime}+\frac{\widehat{Q}^{\prime}(S)[\widehat{Q}(S)-\delta S](n+1-n R) P^{\prime}}{n(r+\delta)}
$$




\section{Proof}

Recall that $\widehat{Q}(S)$ denotes the feedback control rule that achieves the social optimum in the planning problem of Section 2. We want to find a tax rule $\widehat{\tau}(S)$ such that the feedback representation of the OLNE is identical to $\widehat{Q}(S)$. This is achieved if (i) the pair $\{\widehat{Q}(S), \widehat{\tau}(S)\}$ satisfy equation (25) and (ii) $\widehat{\tau}\left(\widehat{S}_{\infty}\right)$ satisfies the steady-state condition for an OLNE, equation (28). Condition (i) means that the following equation must be satisfied:

$$
\frac{P^{\prime}}{n}[n+1-R] \frac{d \widehat{Q}(S)}{d t}=\left[P-c-\tau(S)+\frac{\widehat{Q}}{n} P^{\prime}\right](r+\delta)+\left[\frac{d \widehat{S}}{d t}-\frac{\widehat{Q}}{n}\right] \tau^{\prime}(S)
$$

where $P=P(\widehat{Q}(S)), R=R(\widehat{Q}(S))$, and $P^{\prime}=P^{\prime}(\widehat{Q}(S))$. Replacing $d \widehat{S} / d t$ by $\widehat{Q}(S)-\delta S$ and $d \widehat{Q}(S) / d t$ by $\widehat{Q}^{\prime}(S)[\widehat{Q}(S)-\delta S]$ in $(29)$, we obtain a first order linear differential equation in $\tau$ as described in the statement of Proposition 1. The differential equation (27) has the general solution

$$
\tau(S)=K \exp \left[\int_{0}^{S}-A(\widetilde{S}) d \widetilde{S}\right]+\tau^{p}(S)
$$

where $\tau^{p}(S)$ is a particular solution of $(27)$, and $K$ is a constant. This constant is determined by the boundary condition (28).

Proposition 2: (Optimal tax rule for OLNE: the linear-quadratic case).

Under linear demand and quadratic damage cost, the following tax rule guides oligopolists to achieve the social optimum as an OLNE:

$$
\tau(S)=\eta^{*}+\alpha^{*} S
$$

where

$$
\alpha^{*}=\frac{(n+1) \gamma}{n(r+2 \delta)+(1-n) \rho} \geq 0
$$

and

$$
\eta^{*}=\frac{\left[n \gamma-b(r+\delta) \delta-(n r+n \delta+\delta) \alpha^{*}\right] \widehat{S}_{\infty}}{n(r+\delta)}
$$

where $\alpha^{*}>0$ if $\gamma>0 ; \frac{\partial \alpha^{*}}{\partial n}>0$ if $\gamma>0, \frac{\partial \alpha^{*}}{\partial \gamma}>0, \frac{\partial \alpha^{*}}{\partial r}<0, \frac{\partial \alpha^{*}}{\partial \gamma}<0$, and $\eta$ can be positive or negative, and $\rho$ is the negative root of equation (17).

Proof : We want to show that the differential equation (27) has a solution of the form $\tau(S)=\eta+\alpha S$. Substitute $\eta+\alpha S$ for $\tau(S)$ in (27), where $\widehat{Q}(S)$ is given by (16). Collect all terms that have $S$ as a common factor. Since the differential equation must hold for all $S \geq 0$, the sum 
of these terms must be zero. Thus we obtain the required expression for $\alpha^{*}$, which is (32) above. (In obtaining this, we have also made use of (17) for the relationship between $\rho$ and $\gamma$.) Substitute this expression for $\alpha^{*}$ into the collection of terms not involving $S$. This gives (33). These values also satisfy the boundary condition (28). It can be verified that the necessary and sufficient conditions for an OLNE are satisfied. To obtain the partial derivative of $\alpha^{*}$, we first substitute $\rho$ into (32) to get

$$
\alpha^{*}=\frac{2 \gamma}{(2 \delta+r)+\left[\frac{n-1}{n+1}\right]\left[(r+2 \delta)^{2}+4(\gamma / b)\right]^{1 / 2}}
$$

Remark: The tax rule (31) consists of two components: an 'autonomous' component $\eta^{*}$ that is independent of the pollution stock, and a 'pollutioninduced' component, $\alpha^{*} S$.

It is natural that $\alpha^{*}$ is positive if $\gamma>0$. The partial derivatives of $\alpha^{*}$ reported in Proposition 2 also make sense. Thus, the more firms there are, the greater is the tendency for each firm to ignore the effect of its output on the indutry's future tax bill. To counter this incentive, we have to increase $\alpha^{*}$, that is, a greater weight is given to $S$ in the tax function when $n$ is large.

From Proposition 2, $\eta^{*}$ can be positive or negative, depending on parameter values. To see this more clearly, re-write $\eta^{*}$ as

$$
\eta^{*}=\left[z(n) \gamma-\frac{b(r+\delta) \delta}{n}\right] \frac{\widehat{S}_{\infty}}{r+\delta}
$$

where

$$
z(n)=1-\frac{2(r+\delta+(\delta / n))}{r+2 \delta+\left[\frac{n-1}{n+1}\right]\left[(r+2 \delta)^{2}+4 \gamma / b\right]^{1 / 2}}
$$

In (34), the first term , $z(n) \gamma$, contains the damage parameter $\gamma$ while the second term does not. Note that $z(1)<0$, and $z(n)$ is a increasing function, with $\lim _{n \rightarrow \infty} z(n)>0$. Therefore $\eta<0$ if $n$ is small (for example $n=1$ ), but for $n$ sufficiently great, we have $\eta^{*}>0$. Again, this accords with intuition: If there are just a few firms, then when the stock of pollution is low, an output subsidy is optimal, because the under-production due to market power outweighs the tendency for overproduction associated with negative externality. If there are many firms, then it is never optimal to subsidize outputs.

A somewhat surprising result emerges: even in the case where the laissez-faire output exceeds the socially optimal one at all point of time, 
it may still be optimal to pay firms a subsidy for some initial interval of time, when the stock of pollution is low. (That is, $\tau(S)=\eta^{*}+\alpha^{*} S$ is negative for $S$ sufficiently small.) This subsidy, however, does not induce firms to produce more than their laissez-faire output, because they know that the greater is their output, the quicker is the rate at which the subsidy falls, and if the stock of pollution becomes sufficiently great, $\tau$ will become positive, that is, the subsidy will turn into a tax. In order to receive the subsidy, and to prolong the subsidized phase, firms have an incentive to reduce output below the laissez-faire level. We record this as a proposition.

\section{Proposition 3 (A subsidy that reduces output)}

If the damage parameter $\gamma$ is sufficiently great, then it can be optimal to subsidize firms when the stock of pollution is small, even though their laissez-faire output exceeeds the social optimum at all $t$. This subsidy induces firms to reduce their output below the laissez-faire output.

Proof

It suffices to consider the linear-quadratic case. The laissez-faire output (that is, in the absence of tax or subsidy) is $\bar{Q}=n a /[b(n+1)]$. Since $\widehat{Q}(S)$ is decreasing in $S, \bar{Q}$ exceeds the social optimum output for all value of $S$ if and only if $\bar{Q}>\widehat{Q}(S)$ at $S=0$, that is, if and only if

$$
\left[\frac{2 n}{n+1}\right]\left[1+\frac{\gamma}{\delta b(r+\delta)}\right]>\left[(r+2 \delta)^{2}+4(\gamma / b)\right]^{1 / 2}-r
$$

This is satified for $\gamma$ sufficiently great and both $\delta$ and $r$ are small. If $z(n)$ in (35) is negative (for example, if $n=1$ ) then $\tau(S)<0$ for small $S . \square$

\section{Corrective Tax in a Markov Perfect Nash Equilibrium}

We now turn to the case where firms choose Markovian strategies rather than open-loop strategies. A (stationary) Markovian strategy for a firm is a decision rule that determines its output at time $t$ as a function of the observed size of the pollution stock at $t: q_{i}(t)=\chi_{i}(S(t))$. Under these strategies firms are not committed at the outset to any given time path of their outputs. A Markov perfect Nash equilibrium is a set of decision rules $\chi_{1}(),. \ldots, \chi_{n}($.$) such that each firm's decision rule is the$ best response to those of its opponents.

Suppose firm 1 knows that all other firms use Markovian strategies. Then its optimal response $\chi_{i}($.$) is the solution of an optimal control$ 
problem. Firm 1 knows that the actual outputs of its opponents at time $t$ depends (indirectly) on its output $q_{1}\left(t^{\prime}\right)$ for all $t^{\prime}<t$ via its effect on the stock $S(t)$. Firm 1's optimal solution is then a function of the decision rules of its opponents. Given these decision rules, the solution of firm 1's optimal control problem determines its output at any time $t$ as a function of $S(t)$. We denote this function as $q_{1}(t)=\chi_{1}(S(t))$. The function $\chi_{1}(S)$ is thus a stationary Markovian strategy.

As in Section 3, we assume that the government announces at time $t=0$ a tax rule. For simplicity, we will consider only a per unit tax that depends only on $S: \tau=\tau(S)$. Let

$$
Q_{-i}(S)=\sum_{j \neq i} \chi_{j}(S)
$$

Firm $i$ 's optimal control problem is

$$
\max \int_{0}^{\infty} \pi_{i}(t) e^{-r t} d t
$$

where

$$
\pi_{i}(t)=P\left[Q_{-i}(S)+q_{i}\right] q_{i}-[c+\tau(S)] q_{i}
$$

The constraints are

$$
\dot{S}=Q_{-i}(S)+q_{i}-\delta S
$$

and $q_{i} \geq 0, S(0)=S_{0}$. The Hamiltonian is

$$
H=P\left[Q_{-i}(S)+q_{i}\right] q_{i}-[c+\tau(S)] q_{i}+\lambda_{i}\left[Q_{-i}(S)+q_{i}-\delta S\right]
$$

Restricting attention to interior solutions, we obtain the following necessary conditions for this optimal control problem:

$$
\begin{gathered}
P+q_{i} P^{\prime}-c-\tau(S)=-\lambda_{i} \\
\dot{\lambda}_{i}=\lambda_{i}\left[r+\delta-Q_{-i}^{\prime}(S)\right]+q_{i} \tau^{\prime}(S)-q_{i} P^{\prime} Q_{-i}^{\prime}(S)
\end{gathered}
$$

We now seek to characterize symmetric MPNE, where for all $j, q_{j}=$ $\chi(S)$. Substitute this into (39), and differentiate the resulting expression with respect to $t$ :

$$
\left[(n+1) P^{\prime}(n \chi(S))+n \chi P^{\prime \prime}\right] \chi^{\prime}(S) \dot{S}-\tau^{\prime}(S) \dot{S}=-\dot{\lambda}
$$

Combining this equation with (40), we obtain a differential equation in $\chi$

$$
\left[\chi^{\prime}(S) \psi(\chi(S))-\tau^{\prime}(S)\right][n \chi(S)-\delta S]=\phi\left[\chi(S), \tau(S), \chi^{\prime}(S), \tau^{\prime}(S)\right]
$$


where

$$
\psi[\chi(S)] \equiv(n+1) P^{\prime}(n \chi(S))+n \chi(S) P^{\prime \prime}(n \chi(S))
$$

and

$\phi \equiv\left[P+\chi(S) P^{\prime}-c-\tau(S)\right]\left[r+\delta-(n-1) \chi^{\prime}\right]+\chi(S)\left[(n-1) P^{\prime} \chi^{\prime}-\tau^{\prime}\right]$

Given the tax rule $\tau$, a symmetric MPNE that admits a steadystate is a solution to the differential equation (42) with the 'boundary condition'

$$
n \chi\left(S_{\infty}\right)-\delta S_{\infty}=0
$$

where $S_{\infty}$ is unspecified. We are interested in a MPNE that gives rise to a converging time path of $S$. The following proposition shows that such a MPNE can be easily computed in a special case.

Proposition 4 : Assume linear demand and quadratic damage cost. If the tax rule is linear, $\tau(S)=\eta+\alpha S$, where $\alpha>0$, then there exists a unique symmetric MPNE in linear strategies, $\chi(S)=g-h S$, with $g>0, h>0$, that ensure the convergence of $S(t)$ to a steady state.

Proof: See the Appendix.

Remark: Since best replies to linear strategies are linear, we are not imposing the requirement that, in responding to the linear strategies of its rivals, a firm is restricted to the set of linear strategies.

Proposition 5 :(Optimal tax rule for MPNE : the general case) Under general (non-linear) demand and damage function, a tax rule that guides the firms to achieve the social optimum path as a symmetric MPNE is the solution of the following linear differential equation:

$$
\tau(S)+E(S) \tau^{\prime}(S)=F(S)
$$

with the boundary condition

$$
\left[P\left(\widehat{Q}_{\infty}\right)-c-\tau\left(\widehat{S}_{\infty}\right)\right]=\frac{\left[\tau^{\prime}\left(\widehat{S}_{\infty}\right)-(r+\delta) P^{\prime}\left(\widehat{Q}_{\infty}\right)\right] \widehat{Q}_{\infty}}{\left[n(r+\delta)-(n-1) \widehat{Q}^{\prime}\left(\widehat{S}_{\infty}\right)\right]}
$$

where

$$
E(S) \equiv \frac{n \delta S-(n-1) \widehat{Q}(S)}{n(r+\delta)-(n-1) \widehat{Q}^{\prime}(S)}
$$

and

$$
F(S) \equiv P-c+\frac{1}{n} \widehat{Q} P^{\prime}-P^{\prime} \widehat{Q^{\prime}}\left[\frac{(n+1-R)(\widehat{Q}-\delta S)-\frac{n-1}{n} \widehat{Q}}{n(r+\delta)-(n-1) \widehat{Q}^{\prime}(S)}\right]
$$


Proof: Omitted. The method is similar to that used in the proof of Proposition 1.

Proposition 6 :(Optimal tax rule for MPNE: the linear-quadratic case) For the linear-quadratic case, the optimal tax that guides firms to achieve the social optimum path as a MPNE is

$$
\tau(S)=\eta^{* *}+\alpha^{* *} S
$$

where

$$
\alpha^{* *}=\frac{(n+1) \gamma+(n-1) b \rho^{2}}{n(r+2 \delta)-2(n-1) \rho}>0
$$

and

$$
\eta^{* *}=\left[\frac{\gamma}{r+\delta}-\frac{\delta b(r+\delta)+(n r+n \delta+\delta+n \rho-\rho) \alpha^{* *}}{n(r+\delta)-(n-1) \rho}\right] \widehat{S}_{\infty}
$$

\section{Remark}

It can be verified that if $n>1$ then $\alpha^{* *}<\alpha^{*}$ of the open loop case. The proof consists of showing that $\alpha^{* *}$ is decreasing in $n$ for $n>1$, and noting that if $n=1$ then $\alpha^{* *}=\alpha^{*}$. On the other hand, one can show that $\eta^{* *} \geq \eta^{*}$, with equality holding only if $n=1$. These results are intuitively plausible. If there is only one firm, $(n=1)$, then OLNE is the same as MPNE. If $n \geq 2$, then in an OLNE each firm thinks its rivals will not react to any increase in pollution caused by its increased output. That explains why the government must set $\alpha^{*}$ at a value greater than its MPNE counterpart $\alpha^{* *}$.

\section{$5 \quad$ Concluding remarks}

We have shown that one can find a tax rule that guides oligopolists to achieve the socially optimal time path of pollution. The tax rule is time-independent and therefore does not give rise to dynamic inconsistency. At low pollution levels, the tax can be negative, even when the laissez-faire output exceeds the optimal output at each point in time. In such cases, the firms receiving the subsidy actually have an incentive to produce less than the laissez-faire output. This is because they want to delay the time when the subsidy automatically turns into a tax.

In the case of linear demand and quadratic damage cost, the optimal tax rule turns out to be very simple, and intuitively appealing. It is linear in the pollution stock, and contains only two components, an "autonomous" one which is independent of the pollution stock, and a "pollution-induced" component. It may be argued that if the economy 
is near an optimal steady state, then the linear- quadratic case is a good approximation,

In our formulation, to facilitate comparison of our model with the intertemporal models of Bergstrom et al. (1981) and Karp and Livernois (1992), we have assumed that the marginal cost of public fund is unity. An obvious extension would be to allow this cost to exceed unity. A more difficult task would be to introduce asymmetry of information into our intertemporal framework. This is part of our research agenda.

\section{A Appendix}

\section{Open-loop Nash equilibrium : the linear-quadratic case}

Take any arbitrary pair $(\eta, \alpha)$ with $\alpha \geq 0$, and let $\tau(S)=\eta+\alpha S$. Substituting this into (25) and writing $Q=\dot{S}+\delta S$ and $\dot{Q}=\ddot{S}+\delta \dot{S}$ , we obtain a second order differential equation in $S$. This yields the characteristic equation $\beta^{2}+E \beta+F=0$ where

$$
E=-r+\frac{(n-1) \alpha}{(n+1) b}
$$

and

$$
F=-\delta(r+\delta)-\frac{\alpha}{b}\left[\delta+\frac{r n}{n+1}\right]
$$

We choose the negative root, denoted by $\beta^{o l}$, to obtain the solution that leads to the steady state, that is the point $(\dot{S}, S)=\left(0, S_{\infty}^{o l}\right)$. The steady state pollution stock is

$$
S_{\infty}^{o l}=\frac{a-\eta}{\delta b\left(1+\frac{1}{n}\right)+\alpha\left(1+\frac{\delta}{n(r+\delta)}\right)}
$$

and the equilibrium evolution of $S$ is

$$
S(t)=S_{\infty}^{o l}+\left(S_{0}-S_{\infty}^{o l}\right) \exp \left(\beta^{o l} t\right)
$$

Since $Q=\dot{S}+\delta S$, the equilibrium strategy for firm $i$ is

$$
q_{i}(t)=\frac{1}{n}\left[\delta S_{\infty}^{o l}+\left(\delta+\beta^{o l}\right)\left(S_{0}-S_{\infty}^{o l}\right) \exp \left(\beta^{o l} t\right)\right]
$$

where $\left(\delta+\beta^{\text {ol }}\right)<0$. The feedback representation of the OLNE is obtained from (52) and (53):

$$
Q(S)-Q_{\infty}^{o l}=\left(\delta+\beta^{o l}\right)\left(S-S_{\infty}^{o l}\right)
$$


Markov-Perfect Nash equilibrium : the linear-quadratic case

Using the "undetermined coefficient technique" (see Ferhstman and Kamien (1987), Dockner and Long (1994)) we obtain a unique MPNE in linear strategies that ensure convergence to a steady state. The method is outlined below.

Given the tax rule $\tau(S)=\eta+\alpha S$, where $\alpha>0$, and $a-\eta>0$, let us suppose that firm $i$ assumes that all other firms use a linear Markovian strategy $q_{j}(S)=X+Y S$. (Since $\alpha>0$, we expect $Y$ to be negative in a symmetric MPNE; this will be confirmed later.) Firm $i$ 's profit is

$$
\pi_{i}=\left[a-b\left(q_{i}+(n-1)(X+Y S)\right)\right] q_{i}-(\eta+\alpha S) q_{i}
$$

Let $V_{i}(S)$ be firm $i$ 's value function. The Bellman equation is

$$
r V_{i}(S)=\max _{q_{i}}\left[\pi_{i}+V_{i}^{\prime}(S)\left(q_{i}+(n-1)(X+Y S)-\delta S\right)\right]
$$

Try $V_{i}(S)=\frac{1}{2} A S^{2}+B S+C$, where $A, B$ and $C$ are to be determined. Maximizing the right-hand side of (56) with respect to $q_{i}$ yields

$$
a-\eta-\alpha S-b(n-1)(X+Y S)-2 b q_{i}+A S+B=0
$$

In a symmetric equilibrium, $q_{i}=q_{j}=X+Y S$. Substitute this into (57) to obtain

$$
Y=\frac{A-\alpha}{b(n+1)} \quad, \quad X=\frac{a-\eta+B}{b(n+1)}
$$

Substitute (58) into (56) to obtain an identity which holds for all $S$. Collecting the terms that have $S^{2}$ as a common factor, we obtain a quadratic equation in $A$

$$
2 n^{2} A^{2}-\left[2 \alpha\left(1+n^{2}\right)+b(n+1)^{2}(2 \delta+r)\right] A+2 \alpha^{2}=0
$$

This equation has two real roots

$$
A_{1,2}=\frac{1}{4 n^{2}}\left[2 \alpha\left(1+n^{2}\right)+b(r+2 \delta)(1+n)^{2} \pm \sqrt{Z+\left[b(r+2 \delta)(1+n)^{2}\right]^{2}}\right]
$$

where

$$
Z=4 \alpha^{2}\left(n^{2}-1\right)^{2}+4 \alpha\left(1+n^{2}\right) b(n+1)^{2}(r+2 \delta)>0
$$

It can be shown that the smaller root, say $A_{1}$, is smaller than $\alpha$. This is the one we select to ensure that $Y<0$ (and that $B<0$, and $a-\eta+B>0$, see below). 
Next, collecting the terms that have $S$ as a common factor, we obtain a linear equation in $B$, which gives

$$
B=\frac{(a-\eta)\left[\left(n^{2}+1\right) A_{1}-2 \alpha\right]}{b(r+\delta)(n+1)^{2}+\alpha\left(1+n^{2}\right)-2 n^{2} A_{1}}<0
$$

(It can be shown that denominator of $B$ is positive and the numerator of $B$ is negative.)

Having found $A$ and $B$, we obtain the equation

$$
\dot{S}=n X-n Y S-\delta S=\frac{n[a-\eta+B]}{(n+1) b}+\beta^{M} S
$$

where

$$
\beta^{M} \equiv\left[-\delta+\frac{n\left(A_{1}-\alpha\right)}{(n+1) b}\right]<0
$$

and it can be verified that $a-\eta+B>0$.The steady state stock of pollution in a MPNE, denoted by $S_{\infty}^{M}$, is:

$$
S_{\infty}^{M}=\frac{n[a-\eta+B]}{\left[-b(n+1) \beta^{M}\right]}>0
$$

The equilibrium Markov-perfect strategy is

$$
q_{i}(S)=\frac{1}{n} \delta S_{\infty}^{M}+\frac{1}{n}\left(\delta+\beta^{M}\right)\left(S-S_{\infty}^{M}\right)
$$

This gives rise to the equilibrium industry output

$$
Q(S)-\delta S_{\infty}^{M}=\left(\delta+\beta^{M}\right)\left(S-S_{\infty}^{M}\right)
$$

This is readily comparable with the feedback representation of the OLNE given by (54). $\square$ 


\section{References}

[1] Baron, D. (1989), Design of regulatory mechanisms and institutions, in R. Schmalensee and R. D. Willig, eds., Handbook of Industrial Organization, New York: North Holland, 1347-1447.

[2] Besanko, D. and D. Sappington (1987), Designing Regulatory Policy with Limited Information, London: Harwood Acaemic Publishers.

[3] Bergstrom, T., Cross, J. and R. Porter (1981), Efficiency-inducing taxation for a monopolistically supplied depletable resource, Journal of Public Economics 15, 23-32.

[4] Dockner, E. and N. V. Long (1994), International pollution control: cooperative versus non-cooperative strategies, Journal of Environmental Economics and Management 24, 13-29.

[5] Ferhstman, C. and M. Kamien (1987), Dynamic duopolistic competition with sticky prices, Econometrica 55, 1151-64.

[6] Farzin, Y. H. (1996), Optimal pricing of environmental and natural resource use with externalities, Journal of Public Economics 62, $31-57$.

[7] Fudenberg, D. and J. Tirole (1991), Game Theory, MIT Press, Cambridge, Mass.

[8] Gaudet, G., P. Lasserre, and N.V. Long (1995), Optimal resource royalties with unknown and temporally independent extraction cost structure, International Economic Review 36, 715-49.

[9] Gaudet, G., P. Lasserre, and N.V. Long (1996a), Dynamic incentive contracts with uncorrelated private information and historydependent outcomes, Japanese Economic Review 47, 321-34.

[10] Gaudet, G., P. Lasserre, and N.V. Long (1996b), Real investment decisions under information constraints, CIRANO Working Paper 95s-33, CIRANO, Montreal.

[11] Karp, L. and J. Livernois (1992), On efficiency-inducing taxation for a non-renewable resource monopolist, Journal of Public Economics $49,219-39$. 
[12] Karp, L. and J. Livernois (1994), Using automatic tax changes to control pollution emissions, Journal of Environmental Economics and Management 27, 38-48.

[13] Karp, L. and D. Newbery (1993) Intertemporal consistency issues in depletable resources, Chapter 19 in A. V. Kneese and J. L. Sweeney, eds., Handbook of Natural Resource and Energy Economics, Elsevier Science Publishers, Amsterdam. 881-931.

[14] Katsoulacos, Y. and A. Xepapadeas (1992), Pigouvian taxes under Oligopoly, typescript, Athens Uiniversity.

[15] Kennedy, P. (1994), Equilibrium pollution taxes in open economies with imperfect competition, Journal of Environmental Economics and Management 27, 49-63.

[16] Laffont, J.-J. and J. Tirole (1988), The dynamics of incentive contracts, Econometrica 56, 1153-75.

[17] Laffont, J.-J. and J. Tirole (1996a), Pollution permits and compliance strategies, Journal of Public Economics 62, 85-125.

[18] Laffont, J.-J. and J. Tirole (1996b), Pollution permits and environmental innovation, Journal of Public Economics 62, 127-140.

[19] Leonard, D. and N. V. Long (1992), Optimal Control Theory and Static Optimization in Economics, Cambridge University Press, New York.

[20] Long, N. V. (1992), Pollution control: a differential game approach, Annals of Operations Research 37, 549-69.

[21] Long, N. V. and S. Soubeyran (1997), Cost manipulation in oligopoly: a duality approach, Typescript, McGill University.

[22] Newbery, D. (1990), Acid rain, Economic Policy 11, 298-346.

[23] Sappington, D. and D. Sibley (1988), Regulating without cost information: the incremental surplus subsidy scheme, International Economic Review 29, 297-306.

[24] Sartzetakis, E. (1996), Power in the emission permits markets and its effects on product market structure, Working Paper 59.96, Foundation Mattei.

[25] von der Fehr, N.-H. (1993), Tradeable emission rights and strategic interactions, Environmental and Resource Economics 3, 129-51. 


\section{Liste des publications au CIRANO .}

\section{Cahiers CIRANO / CIRANO Papers (ISSN 1198-8169)}

96c-1 Peut-on créer des emplois en réglementant le temps de travail ? / par Robert Lacroix

95c-2 Anomalies de marché et sélection des titres au Canada / par Richard Guay, JeanFrançois L'Her et Jean-Marc Suret

95c-1 La réglementation incitative / par Marcel Boyer

94c-3 L'importance relative des gouvernements : causes, conséquences et organisations alternative / par Claude Montmarquette

94c-2 Commercial Bankruptcy and Financial Reorganization in Canada / par Jocelyn Martel

94c-1 Faire ou faire faire : La perspective de l'économie des organisations / par Michel Patry

\section{Série Scientifique / Scientific Series (ISSN 1198-8177)}

97s-22 Comparing Open-Loop with Markov Equilibria in a Class of Differential Games / Ngo Van Long, Koji Shimomura et Harataka Takahashi

97s-21 Efficiency Inducing Taxation for Polluting Oligopolists / Hassan Benchekroun et Ngo Van Long

97s-20 Tests of Conditional Asset Pricing Models in the Brazilian Stock Market / Marc Bonomo et René Garcia

97s-19 Nonparametric Methods and Option Pricing / Eric Ghysels, Valentin Patilea, Éric Renault et Olivier Torrès

97s-18 A vailability and Accuracy of Accounting and Financial Data in Emerging Markets: The Case of Malaysia / Jean-Marc Suret, Cameron Morrill et Janet Morrill

97s-17 L'évolution des structures financières des grandes entreprises canadiennes / Jean-Marc Suret et Jean-François L'Her

97s-16 Le régime d'épargne-actions du Québec : Vue d'ensemble et évaluation / Jean-Marc Suret et Élise Cormier

97s-15 Liberalization, Political Risk and Stock Market Returns in Emerging Markets / Jean-Marc Suret, Jean-François L'Her

97s-14 Methods of Pay and Earnings: A Longitudinal Analysis / Daniel Parent

97s-13 A Note on Hedging in ARCH and Stochastic Volatility Option Pricing Models / René Garcia et Éric Renault

97s-12 Equilibrium Asset Prices and No-Arbitrage with Portfolio Constraints / Jérôme B. Detemple et Shashidhar Murthy

97s-11 Aggregation, Efficiency and Mutual Fund Separation in Incomplete Markets / Jérôme B. Detemple et Piero Gottardi

- Vous pouvez consulter la liste complète des publications du CIRANO et les publications elles-mêmes sur notre site World Wide Web à l'adresse suivante :

http://www.cirano.umontreal.ca/publication/page1.htm 